\title{
UV-B Exposure of Black Carrot (Daucus carota ssp. sativus var. atrorubens) Plants Promotes Growth, Accumulation of Anthocyanin, and Phenolic Compounds
}

\author{
Renate Müller ${ }^{1}{ }^{(}$, José R. Acosta-Motos ${ }^{2,3}{ }^{\circledR}$, Dominik K. Großkinsky $4,5 \oplus$, \\ José A. Hernández ${ }^{2}$ (D) Henrik Lütken ${ }^{1}(\mathbb{D})$ and Gregorio Barba-Espin ${ }^{1,2, *(D)}$, \\ 1 Section for Crop Sciences, Department of Plant and Environmental Sciences, Faculty of Science, \\ University of Copenhagen, Hoejbakkegaard Alle, 9-13, 2630 Taastrup, Denmark; ren@plen.ku.dk (R.M.); \\ hlm@plen.ku.dk (H.L.) \\ 2 Department of Fruit Breeding, CEBAS-CSIC, Campus de Espinardo, 30100 Murcia, Spain; \\ jacosta@cebas.csic.es (J.R.A.-M.); jahernan@cebas.csic.es (J.A.H.) \\ 3 Universidad Católica San Antonio de Murcia, Campus de los Jerónimos, 30107 Murcia, Spain \\ 4 Section for Transport Biology, Department of Plant and Environmental Sciences, Faculty of Science, \\ University of Copenhagen, Thorvaldsensvej 40, 1871 Frederiksberg C, Denmark; \\ dominik.grosskinsky@ait.ac.at \\ 5 AIT Austrian Institute of Technology $\mathrm{GmbH}$, Center for Health and Bioresources, Bioresources Unit, \\ Konrad-Lorenz-Straße 24, 3430 Tulln, Austria \\ * Correspondence: gbespin@cebas.csic.es; Tel.: +34-968-396200
}

Received: 22 May 2019; Accepted: 16 June 2019; Published: 19 June 2019

\begin{abstract}
Black carrot (Daucus carota L. ssp. sativus var. atroburens) is a root vegetable with anthocyanins as major phenolic compounds. The accumulation of phenolic compounds is a common response to UV-B exposure, acting as protective compounds and as antioxidants. In the present study, black carrot plants grown under a 12-h photoperiod were supplemented with UV-B radiation $\left(21.6 \mathrm{kj} \mathrm{m}^{-2}\right.$ day $\left.^{-1}\right)$ during the last two weeks of growth. Carrot taproots and tops were harvested separately, and the effect of the UV-B irradiance was evaluated in terms of size (biomass and length), total monomeric anthocyanin content (TMC), total phenolic content (TPC), and phytohormones levels. The results showed that UV-B irradiance promoted plant growth, as shown by the elevated root $(30 \%)$ and top (24\%) biomass, the increased TMC and TPC in the root (over 10\%), and the increased TPC of the top (9\%). A hormone analysis revealed that, in response to UV-B irradiance, the levels of abscisic acid (ABA), jasmonic acid (JA), and salicylic acid (SA) decreased in tops while the level of the cytokinins cis-zeatin (cZ) and trans-zeatinriboside (tZR) increased in roots, which correlated with an amplified growth and the accumulation of anthocyanins and phenolic compounds. Beyond the practical implications that this work may have, it contributes to the understanding of UV-B responses in black carrot.
\end{abstract}

Keywords: anthocyanins; black carrot; phenolic compounds; phytohormones; UV-B irradiance

\section{Introduction}

Domesticated carrot is a root vegetable of which the colour ranges from orange (Daucus carota L. ssp. sativus var. sativus) to purple or black cultivars (Daucus carota L. ssp. sativus var. atroburens), with anthocyanins as major secondary metabolites [1]. The main interest in black carrot anthocyanins is related to their high ratio of mono-acylated structures with three sugar moieties, which provide a high physicochemical stability to the colour extracts and make black carrot suitable for developing natural 
colourants (labelled E163 in Europe) [2]. In addition to anthocyanins, black carrot taproot is a rich source of non-anthocyanin phenolic compounds, mainly consisting of hydroxycinnamic acids and derivatives [3]. The content of phenolic compounds is highly correlated with the strong antioxidant activity of the taproot extract, which in turn is associated with the potential health benefits of black carrot in preventing cardiovascular and neuronal diseases, among other diseases [3,4]. Although at much lower concentrations than in the taproot, phenolic compounds are also present in carrot leaves [5].

Phenolic compounds act as non-enzymatic antioxidants, scavenging reactive oxygen species (ROS) and participating in the response to stress [6]. In this respect, the metabolism and accumulation of phenolic compounds increases under stress conditions such as wounding, pathogen attack, and UV radiation, among others $[7,8]$. Photoprotective roles of foliar phenolic compounds against UV-B radiation have received much attention in recent years. Because of its high energy, this short-wave band of the terrestrial solar spectrum causes damages to RNA, DNA, proteins, and lipids [9]. Consequently, plants accumulate UV-B-absorbing phenolic compounds in the epidermal layers of leaves and stems. Of all classes of phenolic compounds, flavonoids, particularly anthocyanins, are regarded as the main contributors to the UV-B screening capacity of the plant [10].

Although for the past few decades UV-B radiation was mainly regarded as a stressor [11,12], it now appears to have important regulatory roles in plants [13-15]. In this sense, while high UV-B doses are more often associated with detrimental effects, moderate and sub-lethal levels of UV-B have been associated with the stimulation of plant growth via specific signalling, leading to an acclimation state without evident signs of stress $[14,16]$. Until now, the effect of UV-B light has not been investigated neither in carrot in vivo nor in a black carrot variety.

As hormones are widespread in the regulation of plant metabolism and morphogenesis, they are also implicated in UV-B stress response and signalling, participating in systemic signalling networks that ultimately affects plant growth and development [14,17]. Likewise, hormones interact in controlling anthocyanin biosynthesis $[18,19]$. However, the study of phytohormone profiles in carrot has been limited to the flowering process in leaf tissue [20], and the molecular mechanisms underlying differential anthocyanin accumulation in the root in response to above ground stimuli remain unknown. In the present work, we studied for the first time the effects of a moderate dose of supplemental UV-B light on black carrot performance. The levels of phytohormones (abscisic acid, cytokinins, indole-3-acetic, jasmonic acid, jasmonic acid-isoleucine, and salicylic acid), total anthocyanins, and phenolic compounds were determined, establishing a comparison between the plant top and taproot. Taken together, this study increases the knowledge on black carrot phytochemical composition and physiology and contributes to the understanding of the physiological responses to UV-B light.

\section{Materials and Methods}

\subsection{Plant Material and Cultivation}

Seeds of black carrots (Daucus carota L. ssp. sativus var. atrorubens) of "Deep Purple" F1 (Bejo Seeds Inc., Oceano, CA, USA) were sown in 30-cm long cylindrical pots (18 cm in diameter) with $7.5 \mathrm{~L}$ of an equal mixture of garden soil and perlite (particle size 1-5 mm), which provided an adequate balance of air and moisture content around the taproot [21]. Ten sowing spots per pot were distributed, and three seeds were introduced in each one at one-cm depths. Pots (12 in total) were placed in a climate chamber under a $12-\mathrm{h}$ photoperiod $\left(350 \mu \mathrm{mol} \mathrm{m} \mathrm{m}^{-2} \mathrm{~s}^{-1}\right.$ visible light $)$ in a $20^{\circ} \mathrm{C}$ day $/ 18^{\circ} \mathrm{C}$ night cycle. From ten days after sowing, $1 \mathrm{~L} 1 / 2$ Hoagland solution was applied every 3 days until the end of the experiment. Fourteen days after sowing, two seedlings per spot were removed, leaving one vigorous plant per place.

\subsection{UV-B Light Treatment}

Twelve weeks after sowing, the aboveground parts of the carrots plants were treated with supplemental UV-B light $\left(6 \mathrm{~W} \mathrm{~m}^{-2} \mathrm{~s}^{-1}\right.$ radiation fluence rate) during $1 \mathrm{~h}$ per day $\left(21.6 \mathrm{kj} \mathrm{m}^{-2} \mathrm{day}^{-1}\right)$, 
coinciding with the fifth hour of white light of the 12-h photoperiod provided by low irradiance UV-B lamps (Philips Broadband TL40W/12 RS, Eindhoven, The Netherlands) placed at a distance of ca. $1.2 \mathrm{~m}$ from the top of the plants. Radiation was measured using a RM-12 Ultraviolet Light Meter equipped with a UVB sensor (Opsytec Dr. Gröbel GmbH, Ettlingen, Germany).

\subsection{Harvest, Sample Collection, and Processing}

Fourteen days after the initiation of the UV-B light treatment (16 weeks after sowing), plants were harvested, washed, and carefully dried. The length and fresh weight (FW) of the top and taproot of each plant were registered. In the case of the top length, it corresponded to the length of the longest leaf. For further analyses, two types of samples were generated: (1) shoot samples, composed of the pool of leaves and stems of the 10 plants from a pot, and (2) root samples, composed of the corresponding 10 taproots. Subsequently, each combined sample (biological replicate) was ground in liquid nitrogen prior to storage of the resulting powder at $-80^{\circ} \mathrm{C}$.

\subsection{Determination of Total Monomeric Anthocyanin Content (TMC) and Total Phenolic Content (TPC)}

Five grams of the powder generated above was homogenised in a 3\% sulfuric acid solution $(1 / 1, w / w)$ using a Waring ${ }^{\circledR}$ two-speed commercial blender (VWR-Bie \& Berntsen, Herlev, Denmark). The produced homogenate was then vigorously mixed either with (a) water $(1 / 2, w / w)$ for the subsequent analysis of TMC or (b) 70\% ethanol $(1 / 2, w / w)$ for the later analysis of TPC. After $1 \mathrm{~h}$ of incubation at $25{ }^{\circ} \mathrm{C}$, the sample was centrifuged for $20 \mathrm{~min}$ at $4500 \mathrm{rpm}$ and the resulting supernatant was collected [1].

TMC determination was based on the $\mathrm{pH}$ differential method with minor modifications [1]; in brief, the supernatant extracted in water was diluted in a $0.2 \mathrm{M} \mathrm{KCl}-\mathrm{HCl}(\mathrm{pH} 1)$ solution $(1 / 1, v / v)$, and the absorption was measured between 350 and $700 \mathrm{~nm}$ using a UV-visible spectrophotometer (Thermo Scientific Evolution ${ }^{\mathrm{TM}}$ 220, Waltham, MA, USA). The TMC was calculated as cyanidin 3-glucoside equivalents.

TPC was determined by the Folin-Ciocalteau method [22]. In brief, the supernatant extracted in $70 \%$ ethanol was mixed with the Folin-Ciocalteau reagent $(1 / 5, v / v)$, followed by the addition of $20 \%$ $(w / v)$ sodium carbonate $(0.6 / 1, v / v)$. After incubation for $2 \mathrm{~h}$ in the dark, the absorbance was determined at $760 \mathrm{~nm}$ using a UV-visible spectrophotometer (Thermo Scientific Evolution ${ }^{\mathrm{TM}} 220$ ). The TPC was then calculated as mg of gallic acid equivalent (GAE) per $g$ of FW.

\subsection{Phytohormones Determination}

The method setup based on Reference [23] with minor modifications allowed the simultaneous determination of the following hormones and derivatives: abscisic acid (ABA); indole-3-acetic acid (IAA); jasmonic acid (JA); jasmonic acid-isoluecine (JA-Ile); methyl jasmonate (MeJA); salicylic acid (SA); and the cytokinins (CKs) cis-zeatin (cZ), dihydrozeatin (DHZ), dihydrozeatinriboside (DHZR), and trans-zeatin (tZ). In brief, $200 \mathrm{mg}$ ground leaves and $300 \mathrm{mg}$ ground roots (FW) were homogenized in $1.25 \mathrm{~mL} 80 \%$ methanol with the addition of $10 \mu \mathrm{L}$ of internal standard mix (5 ppm in $80 \%$ methanol) composed of the deuterium-labelled hormones (2H5)tZ and (2H6)ABA. The supernatants were filtrated using $80 \%$ methanol-activated C18 columns (Phenomenex, Strata ${ }^{\circledR}$ C18-E, $200 \mathrm{mg} / 3 \mathrm{~mL}$, 8B-S001-FBJ), and the elutes were collected on ice. The pellet was re-extracted in $1.25 \mathrm{~mL} \mathrm{80 \%} \mathrm{methanol.}$ The combined extracts were concentrated to dryness in a SpeedVac system, and the resulting residues were sonicated in $1 \mathrm{~mL} \mathrm{20 \%}$ methanol and passed through 0.2- $\mu \mathrm{m}$ syringe filters (Chromafil PES-20/25). Finally, the samples were analysed using an AdvanceTM-UHPLC/EVOQTMElite-TQ-MS system (Bruker) with a Phenomenex C-18 reversed phase column (Kinetex $1.7 \mathrm{u}$ XB-C18, $10 \mathrm{~cm} \times 2.1 \mathrm{~mm}$, $1.7 \mu \mathrm{m}$ particle size) according to Reference [24], and the results were expressed as pmol g ${ }^{-1} \mathrm{FW}$. 


\subsection{Statistical Analyses}

The analyses were conducted with four to six biological replicates, each of them consisting of the pool of samples from one pot (10 plants). The data were subjected to a statistical analysis using the StatGraphics Centurion XV software (StatPoint Technologies, Warrenton, VA, USA). The treatments were compared using a one-way analysis of variance (ANOVA) followed by a Least Significant Differences post hoc test $(p \leq 0.05)$. The Pearson's correlation coefficient was calculated to measure the linear relationship between pairs of variables. A principal component analysis (PCA) followed by a partial least squares discriminant analysis was conducted to assign the principal components displaying eigenvalues greater than or equal to 1.0, which led to the identification of two principal components explaining $84 \%$ of the variation within the data set.

\section{Results}

In the present work, 12-week-old black carrot plants of "Deep Purple" F1 grown under visible light were subjected to a moderate dose of UV-B radiation concurring with a 12-h photoperiod. After 2 weeks, the plants were harvested, and the effect of the treatment was evaluated on tops and taproots in terms of size (weight and length) and phytochemical composition (total phenolic and anthocyanin contents and phytohormones levels).

Overall, both untreated and UV-B-treated plants displayed undistinguishable taproot appearance and a transversal colour (Figure 1a). Likewise, the plant length was statistically equal in both treatments; control plants displayed mean values of 55.0 and $14.5 \mathrm{~cm}$ and UV-B plants displayed values of 56.3 and $15.3 \mathrm{~cm}$ for the top and taproot lengths, respectively (Figure 1b). By contrast, fresh weights (FWs) of the taproot $(22.5 \mathrm{~g})$ and the top $(43.2 \mathrm{~g})$ of treated plants were significantly higher than those of untreated plants (17.2 and $34.7 \mathrm{~g}$ for taproot and top, respectively) by 30 and 24\%, respectively (Figure 1c). In addition, UV-B light treatment had no impact on the ratio between the FW of tops and roots (1.89) or on the dry weight of tops and roots.

(a)

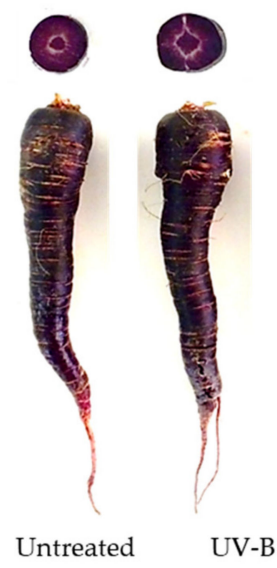

(b)

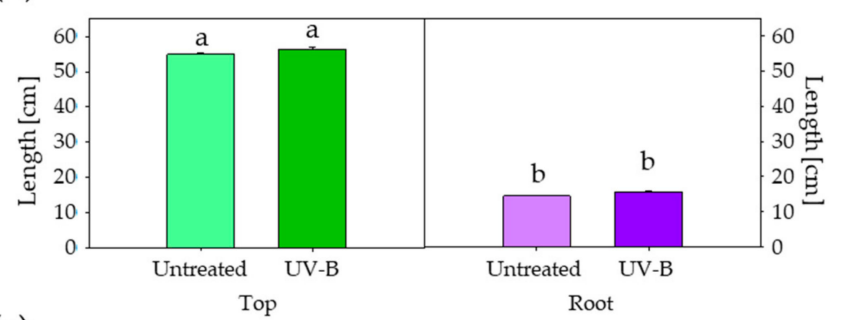

(c)

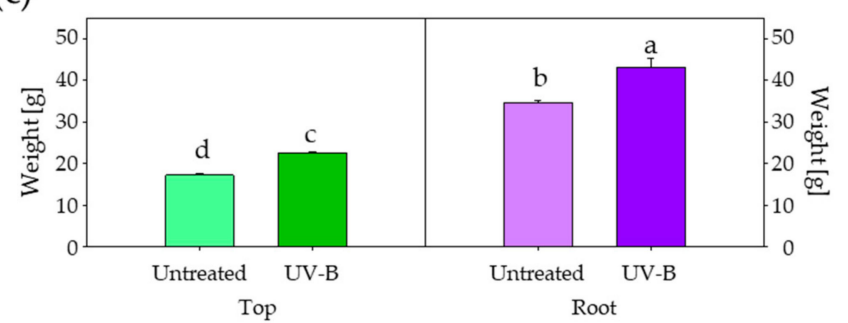

Figure 1. Growth of untreated and UV-B-treated plants of black carrot. (a) Taproot appearance and transversal sections. (b) Top and taproot length. (c) Top and taproot fresh weight. Different letters indicate statistical significances according to the least significant differences test $(p \leq 0.05)$.

Subsequently, the effects of UV-B irradiance on TMC and TPC were analysed (Figure 2). UV-B treatment increased TMC in tops by $10 \%$, exhibiting mean values of 208 and $228 \mu \mathrm{g} \mathrm{g}^{-1}$ FW in untreated and UV-B-treated plants, respectively, although showing no significant differences. As expected, TMC in taproots was remarkably higher than in tops, with values of 1494 and $1694 \mu \mathrm{g} \mathrm{g}^{-1}$ FW in untreated and UV-B-treated plants, respectively, the latter being significantly higher (Figure 2a). 
Similarly, TPC was higher in taproots (2309 and $2612 \mu \mathrm{g} \mathrm{g}^{-1} \mathrm{FW}$ for untreated and treated plants, respectively) than in tops (337.7 and $370.3 \mu \mathrm{g} \mathrm{g}^{-1} \mathrm{FW}$ for untreated and treated plants, respectively) (Figure $2 b$ ). TPC of treated plants was significantly higher than that of control plants, increasing by 9 and $13 \%$ in tops and taproots, respectively (Figure $2 b$ ).

(a)

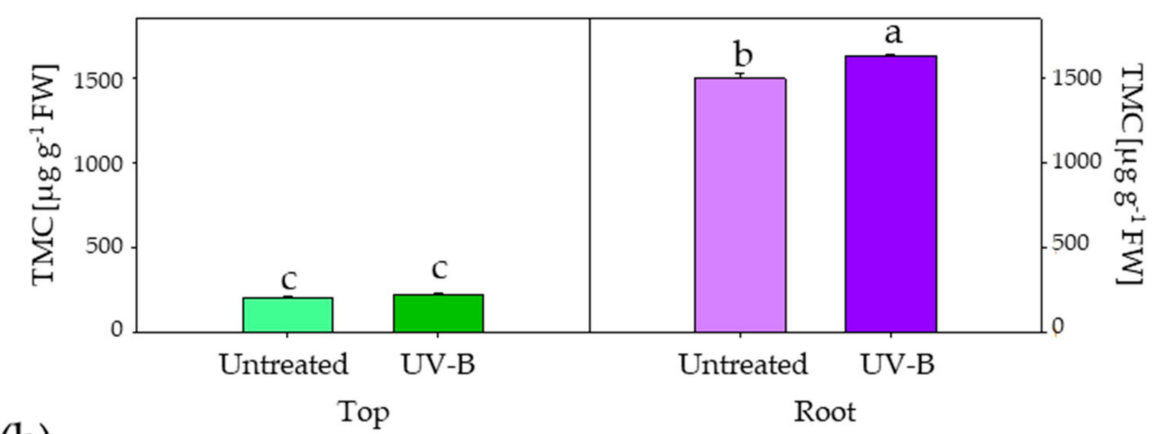

(b)

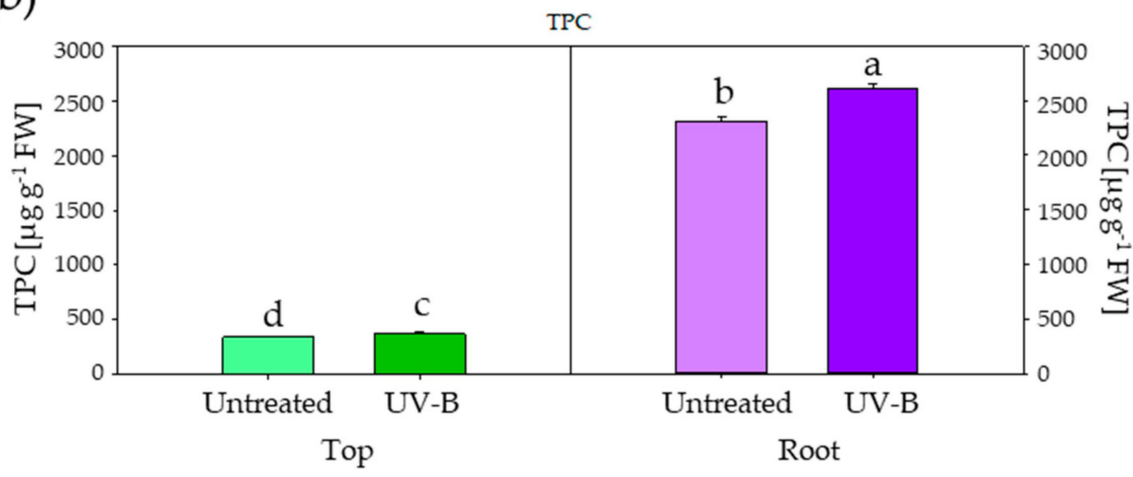

Figure 2. Total monomeric anthocyanins content (TMC) (a) and total phenolics content (TPC) (b) of untreated and UV-B-treated tops and taproots of black carrot. Different letters indicate statistical significances according to the least significant differences test $(p \leq 0.05)$.

The phytohormone analysis allowed the parallel quantification of eight different hormones (ABA, cZ, IAA, JA, JA-Ile, SA, tZR, and tZROG) from one single sample (Figure 3). Two additional ones, MeJA and $t Z$, were not consistently measured in the two experiment repetitions and, therefore, considered as not detected under our experimental conditions. Regardless of treatment, the levels of certain hormones (IAA, JA, JA-Ile, and tZROG) remained higher in tops than in taproots, whereas others (ABA and tZR) displayed the opposite variation. Finally, the levels of SA, the most abundant hormone, were comparable in both organs, whereas $\mathrm{cZ}$ was not detected in tops (Figure 3). 
(a)

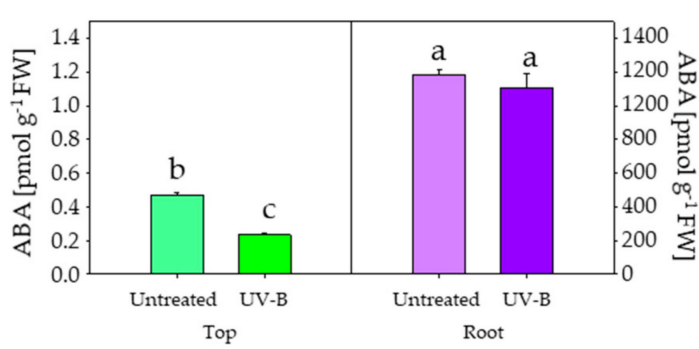

(c)

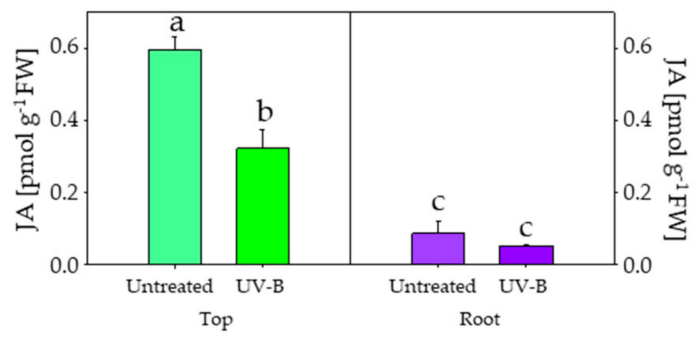

(e)

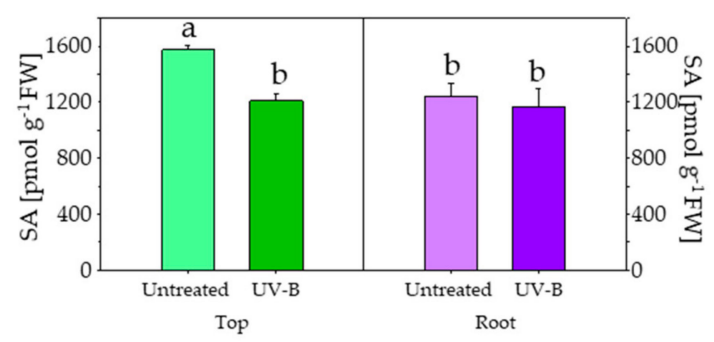

(g)

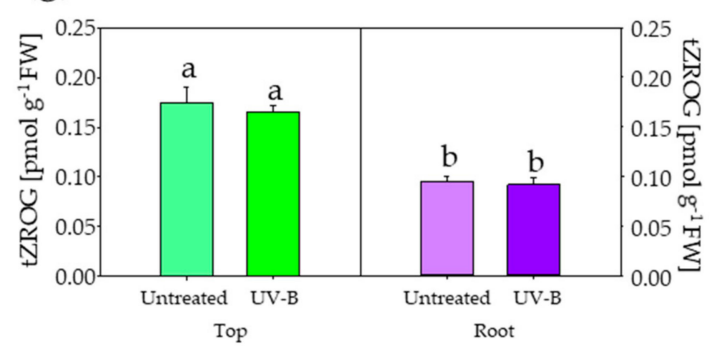

(b)

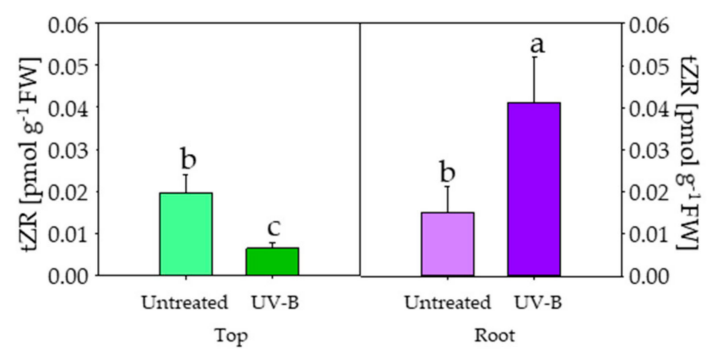

(d)

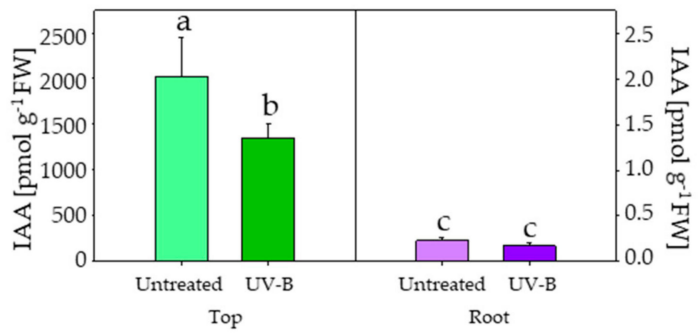

(f)

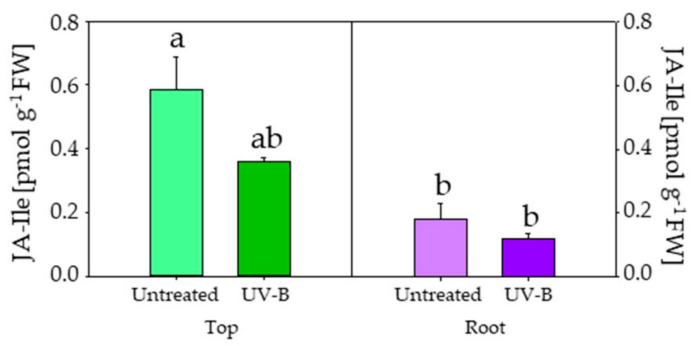

(h)

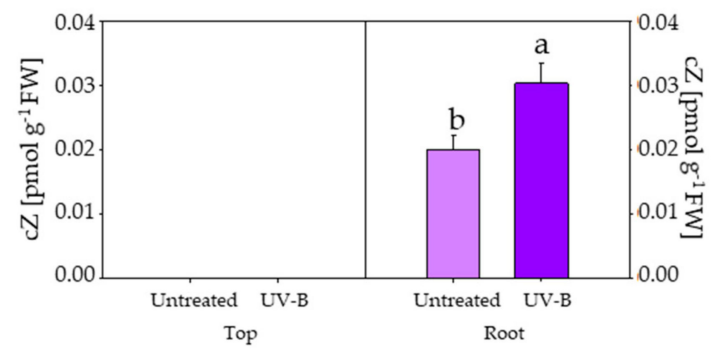

Figure 3. Phytohormones determination on top and root samples of black carrot. ABA: abscisic acid (a); tZR: trans-zeatinriboside (b); JA: jasmonic acid (c); IAA: indole-3-acetic acid (d); SA: salicylic acid (e); JA-Ile: jasmonic acid-isoleucine (f); tZROG: trans-zeatinriboside-O-glucoside (g); and cZ: cis-zeatin (h). Different letters indicate statistical significances according to the least significant differences test $(p \leq 0.05)$.

Regarding the comparison between treatments on carrot tops, hormone levels for ABA, IAA, JA, SA, and tZR decreased significantly upon UV-B treatment. In this respect, the highest variation corresponded to ABA and $\mathrm{tZR}$, where the mean values dropped over $50 \%$ (from 0.47 to 0.23 and 0.041 to $0.020 \mathrm{pmol} \mathrm{g}^{-1} \mathrm{FW}$, respectively) in response to UV-B light treatment, followed by JA, of which the levels decreased by $46 \%$ upon UV-B light treatment, passing from 0.60 to $0.32 \mathrm{pmol} \mathrm{g}^{-1} \mathrm{FW}$ (Figure $3 \mathrm{a}-\mathrm{c}$ ). Likewise, the mean value of IAA reduced from 2020 to $1351 \mathrm{pmol} \mathrm{g}^{-1} \mathrm{FW}$, which represents a $33.1 \%$ decrease (Figure 3d), and the levels of SA passed from 1574 to $1241 \mathrm{pmol} \mathrm{g}^{-1} \mathrm{FW}$ (21\% decrease) (Figure 3e). On the other hand, the levels of JA-Ile and tZROG remained statistically invariable between treatments on carrot tops (Figure 3f,g). 
In roots, a distinct response was found; the cytokinins $c Z$ and tZR increased in UV-B-treated roots with respect to untreated roots, whereas the rest of hormones remained unchanged in both treated and untreated roots. $\mathrm{cZ}$, which was not detected in carrot tops, was found to increase by $50 \%$ upon UV-B light treatment, displaying values of $0.030 \mathrm{pmol} \mathrm{g}^{-1} \mathrm{FW}$, whereas the levels on control taproots remained at $0.019 \mathrm{pmol} \mathrm{g}^{-1} \mathrm{FW}$ (Figure 3h). The levels of tZR for roots of UV-B treated plants $\left(0.041 \mathrm{pmol} \mathrm{g}^{-1} \mathrm{FW}\right)$ more than doubled those found on untreated roots $\left(0.020 \mathrm{pmol} \mathrm{g}^{-1} \mathrm{FW}\right)$ (Figure $3 \mathrm{~b}$ ).

In order to determine any association between variables, a correlation matrix was elaborated (Table 1), which denoted noticeable variations among them. The correlation of greatest magnitude was evenly displayed for TPC and length and for TMC and length (-0.98), followed by TPC and TMC (0.97), whereas coefficients between weight and TPC and between weight and TMC were 0.88 and 0.89 , respectively; this indicates that, rather than length, weight is the main factor associated positively to the levels of TPC and TMC. With respect to hormones, TMC and TPC showed very similar positive (ABA) and negative (IAA, JA, JA-Ile, SA, cZ, tZROG, and tZR) correlations, which demonstrates that the higher TMC and TPC is, the lower the levels of most of the hormones are, and indicates the close association between TMC and TPC. Interestingly, length displayed similar correlation coefficients to TMC and TPC with regard to hormones but with the opposite sign. ABA, JA, and tZROG were the most relevant hormones for the establishment of correlations. Moreover, ABA displayed negative correlations to JA and $\mathrm{tZROG}$. On the other hand, SA and $\mathrm{cZ}$ were the variables displaying fewer correlations.

Table 1. Pearson's correlation coefficients for the variables studied.

\begin{tabular}{|c|c|c|c|c|c|c|c|c|c|c|c|}
\hline & $\mathbf{A B A}$ & IAA & JA & JA-Ile & SA & cZ & t-ZROG & $t-Z R$ & Weight & Length & TMC \\
\hline IAA & $-0.77^{* * *}$ & & & & & & & & & & \\
\hline JA & $-0.84^{* * *}$ & $0.71^{*}$ & & & & & & & & & \\
\hline JA-Ile & $-0.66^{* *}$ & $0.84^{* * *}$ & $0.83 * * *$ & & & & & & & & \\
\hline SA & -0.34 & 0.24 & 0.20 & 0.37 & & & & & & & \\
\hline cZ & $0.72 *$ & -0.21 & 0.04 & -0.04 & $-0.75^{*}$ & & & & & & \\
\hline t-ZROG & $-0.84^{* * *}$ & $0.81 * * *$ & $0.89 * * *$ & $0.77^{* * *}$ & 0.37 & -0.33 & & & & & \\
\hline t-ZR & 0.32 & -0.18 & -0.51 & -0.41 & 0.08 & 0.01 & -0.31 & & & & \\
\hline Weight & $0.86^{* * *}$ & $-0.73^{* * *}$ & $-0.87^{* * *}$ & $-0.69 * *$ & -0.27 & 0.26 & $-0.87^{* * *}$ & 0.31 & & & \\
\hline Length & $-0.97^{* * *}$ & $0.81^{* * *}$ & $0.88^{* * *}$ & $0.68^{* *}$ & 0.24 & -0.03 & $0.83^{* * *}$ & -0.44 & $-0.85^{* * *}$ & & \\
\hline TMC & $0.98^{* * *}$ & $-0.78^{* * *}$ & $-0.88^{* * *}$ & $-0.68^{* *}$ & -0.24 & -0.00 & $-0.85^{* * *}$ & 0.38 & $0.89 * * *$ & $-0.98^{* * *}$ & \\
\hline TPC & $0.98^{* * *}$ & $-0.79 * * *$ & $-0.88^{* * *}$ & $-0.70 * *$ & -0.28 & 0.39 & $-0.83^{* * *}$ & 0.51 & $0.88^{* * *}$ & $-0.98^{* * *}$ & $0.97^{* * *}$ \\
\hline
\end{tabular}

The symbols *,**, and ${ }^{* * *}$ denote statistical significances at $p \leq 0.05, p \leq 0.01$, and $p \leq 0.001$, respectively. ABA: abscisic acid; cZ: cis-zeatin; IAA: indole-3-acetic acid; JA: jasmonic acid; JA-Ile: jasmonic acid-isoleucine; SA: salicylic acid; TMC: total monomeric anthocyanin content; TPC: total phenolic content; tZR: trans-zeatinriboside; and tZROG: trans-zeatinriboside-O-glucoside.

Complementarily, PCA was utilised as a mathematical tool to determine associations between the hormonal and physiological (growth, TPC, and TMC) variables (Figure 4). PCA resulted in a model with two principal components (PCs) explaining $84 \%$ of the total variance (Figure 4). The first PC accounted for $75 \%$, whereas the second explained $9 \%$ of the variance. Two main groups of variables could be easily distinguished from left to right in PC1, showing the loadings for TMC, TPC, weight, ABA, and $\mathrm{cZ}$ clustered in one group and length and the hormones IAA, JA, JA-Ile, and tZROG grouped in the opposite direction with a similar magnitude, which is related to the higher abundance of the levels of the first and second groups in roots and tops, respectively (Figures 1-3). Concerning PC2, two variables, SA and tZR, appeared as the dominant loadings while not showing a relevant contribution to PC1. 


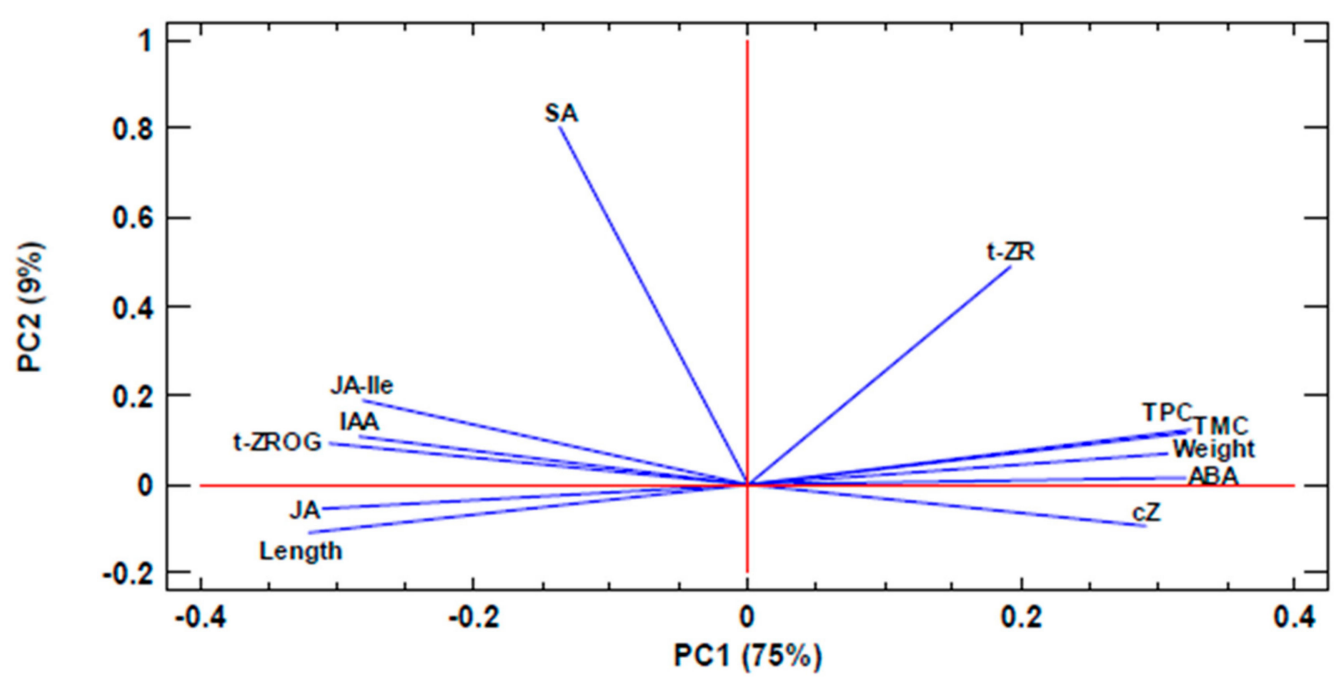

Figure 4. A principal component analysis applied to growth, total phenolic content (TPC), total monomeric anthocyanin content (TMC), and hormone (ABA: abscisic acid; cZ: cis-zeatin; IAA: indole-3-acetic acid; JA: jasmonic acid; JA-Ile: jasmonic acid-isoleucine; SA: salicylic acid; tZR: trans-zeatinriboside; and tZROG: trans-zeatinriboside-O-glucoside) variables. Two principal components (PC1 and PC2) resulted in a model that explained $84 \%$ of the total variance. The arrows denote eigen vectors characterised by the direction and the strength of the variable relative to PC1 and 2.

\section{Discussion}

Numerous publications refer to UV-B-derived physiological and phenotypic changes. These reports are diverse and often show opposite effects, which likely reflect the heterogeneity of experimental conditions and plant material. Moreover, the ecological relevance of the UV treatment has to be taken into consideration in order to distinguish between UV-stress response and acclimation effects $[25,26]$. In the present study, a positive effect of a moderate dose of UV-B irradiance on black carrot performance was achieved. Such an effect was reflected in increased top and root growth and an enhanced accumulation of anthocyanins and phenolic compounds. These changes were associated with changes in the phytohormone profiles of roots and tops, which may cause an improved physiological status, driving growth and anthocyanin accumulation.

A common response to UV light exposure is the increased accumulation of phenolic compounds [27]. The mechanism underlying UV-B perception and the accumulation of photo-protectant phenolic compounds is quite studied in aerial parts of plants [10,28-30]. Moreover, phenolic compounds display antioxidant roles acting as direct scavengers of reactive oxygen species (ROS) [29]. At the cellular level, UV-B irradiance initially triggers ROS formation, which subsequently increases the biosynthesis of certain phenolic compounds, as part of the non-enzymatic antioxidant defences [26,31,32]. This phenomenon would explain the accumulation of these compounds in non-exposed tissues to UV-B, as observed in maize roots [33]. In fact, low UV-B doses increased the flavonoid content in leaves and roots of nasturtium [34] and kale [35], which indicates that UV-B may act as a systemic inducer of phenolic contents in the whole plant. Likewise, in our study, although UV-B resulted in a significant increase of TPC in tops, its effect was more evident in roots, where both TMC and TPC increased by $13 \%$ (Figure 2). This effect may be based on shoot-root signalling events indirectly leading to the accumulation of root phenolics. Moreover, the fact that sampling was not limited to the leaf portions directly exposed to the UV-B light can explain the lower accumulation of phenolic compounds in tops.

A second frequent effect of UV-B irradiance on plant physiology is a decrease in biomass [26]. Such an effect relies on the biosynthesis costs of flavonoids and related phenolic compounds, which are generally higher than those of biomass [36]. Conversely, several authors have reported an increased 
plant biomass in response to moderate UV-B doses in faba bean [33], radish [37], and Arabidopsis [38]. A similar response was found in our work, where both top and root weights increased upon treatment (Figure 1). It can be hypothesised that, given the extraordinary high concentration of anthocyanins and, in general, of phenolic compounds of black carrot roots, the possible oxidative stress following UV-B light exposure would be attenuated by plant defence mechanisms to an extent that no deleterious effects were detected under our experimental conditions.

UV-B interferes with hormonal metabolism and transport $[39,40]$. Overall, among hormones, IAA, cytokinins, and GAs act by promoting plant growth, whereas JA, ABA, and SA inhibit it [38,39]. In agreement with this, in the present study, the levels of the growth-inhibiting hormones ABA, JA, and SA decreased in the tops of treated plants, while the growth-promoting cytokinins $\mathrm{CZ}$ and tZR increased in roots (Figure 3), a response that correlated with the increases in top and root growth (Figure 1c). These modulations may indicate that UV-B radiation aboveground promoted carrot growth through signaling events that trigger cytokinin (cZ and tZR) accumulation in the root. In this sense, decreasing cZ levels caused a reduced root growth in Arabidopsis and rice [41-43], which indicates an active role of $c Z$ in promoting root growth.

In contrast, the levels of IAA notably decreased in treated plants, which may be linked to the inhibition of auxin biosynthesis by UV-B, as reported [44]. UV-B may induce the isomerization of ABA to $50 \%$ trans, trans and $50 \%$ cis, trans [40,45], the latter being the active form; consequently, in tissues where UV-B penetrates, the amount of active ABA may be negatively affected. Among cytokinins, zeatin and its derivatives are the most important group of isoprenoid cytokinins. Although cZ has been generally reported as scarcely active compared to its trans-isomer, recent studies assign physiological functions to this hormone [46]; interestingly, $\mathrm{CZ}$ was quantifiable only in root samples, with its levels lower in UV-B-treated plants. Inactive forms of cytokinins are abundant and serve as a reservoir [47]. In this sense, tZROG, a conjugated inactive form of cytokinin, displayed values an order of magnitude higher than those for $\mathrm{CZ}$ and $\mathrm{tZR}$ in this study.

On the other hand, UV-B typically induces JA and SA, as stress-responsive hormones [40,48], which is contradictory to our findings, where the levels of both hormones decreased in the tops of treated plants. Considering that plants were UV-B treated for 14 days before harvest and sampling, a distinct JA and SA modulation during the first days of treatment cannot be discarded, which at the end of the experiment-likely involving an acclimation response-led to the hormone levels found in this study.

\section{Conclusions}

Collectively, we can assert that moderate UV-B irradiance on black carrot may act simultaneously to induce valuable secondary metabolites accumulation and plant growth. The analysis of the hormones profile-which is supposed as the first study conducted on black carrots-reveals noticeable changes upon UV-B-treatment and sheds light on the regulation of phenolic compounds in the root/ Beyond the practical implications that this work may have regarding the utility of UV-B on anthocyanin production, it represents a stepping-stone towards the understanding of UV-B regulation and stress in black carrot.

Author Contributions: Conceptualization, G.B.E., R.M., and H.L.; methodology, G.B.E., D.K.G., and R.M.; formal analysis, G.B.E. and J.R.A.M.; investigation, R.M. and G.B.E.; data curation, J.R.A.M.; writing-original draft preparation, G.B.E. and J.A.H.; writing-review and editing, R.M., G.B.E, J.A.H., J.R.A.M., H.L., and D.K.G.

Funding: This research was funded by the Danish Ministry of Science, Innovation, and Education grant number 6111-00240B and "Fundación Séneca" of the Agency of Science and Technology of the Region of Murcia grant number 20405/SF/17.

Conflicts of Interest: The authors declare no conflict of interest. 


\section{References}

1. Barba-Espín, G.; Glied, S.; Crocoll, C.; Dzhanfezova, T.; Joernsgaard, B.; Okkels, F.; Lütken, H.; Müller, R. Foliar-applied ethephon enhances the content of anthocyanin of black carrot roots (Daucus carota ssp. sativus var. atrorubens Alef.). BMC Plant Biol. 2017, 17, 70. [CrossRef]

2. Montilla, E.C.; Arzaba, M.R.; Hillebrand, S.; Winterhalter, P. Anthocyanin composition of black carrot (Daucus carota ssp. sativus var. atrorubens Alef.) cultivars Antonina, Beta Sweet, Deep Purple, and Purple Haze. J. Agric. Food Chem. 2011, 59, 3385-3390. [CrossRef] [PubMed]

3. Smeriglio, A.; Denaro, M.; Barreca, D.; D.'Angelo, V.; Germanò, M.P.; Trombetta, D. Polyphenolic profile and biological activities of black carrot crude extract (Daucus carota L. ssp. sativus var. atrorubens Alef.). Fitoterapia 2018, 124, 49-57. [CrossRef] [PubMed]

4. Kähkönen, M.P.; Heinonen, M. Antioxidant activity of anthocyanins and their aglycons. J. Agric. Food Chem. 2003, 51, 628-633. [CrossRef] [PubMed]

5. Burri, S.; Ekholm, A.; Håkansson, Å.; Tornberg, E.; Rumpunen, K. Antioxidant capacity and major phenol compounds of horticultural plant materials not usually used. J. Funct. Foods 2017, 38, 119-127. [CrossRef] [PubMed]

6. Huda-Faujan, N.; Noriham, A.; Abdullah Sani, N.; Babji, A.S. Antioxidant activity of plants methanolic extracts containing phenolic compounds. Afr. J. Biotechnol. 2009, 8, 484-489.

7. Horvath, D.M.; Chua, N.H. The role of salicylic acid in systemic acquired resistance. Curr. Opin. Biotechnol. 1994, 5, 131-136. [CrossRef]

8. Reyes, L.F.; Cisneros-Zevallos, L. Wounding stress increases the phenolic content and antioxidant capacity of purple-flesh potatoes (Solanum tuberosum L.). J. Agric. Food Chem. 2003, 51, 5296-5300. [CrossRef]

9. Heisler, G.M.; Grant, R.H.; Gao, W.; Slusser, J.R. Ultraviolet radiation and its impacts on agriculture and forests. Agric. For. Meteorol. 2003, 120, 3-7. [CrossRef]

10. Jenkins, G.I. The UV-B Photoreceptor UVR8: From Structure to Physiology. Plant Cell 2014, 26, $21-37$. [CrossRef]

11. Caldwell, M.M.; Teramura, A.H.; Tevini, M.; Bornman, J.F.; Björn, L.O.; Kulandaivelu, G. Effects of increased solar ultraviolet radiation on terrestrial plants. In United Nations Environment Programme. Environmental Effects of Ozone Depletion: 1994 Assessment; United Nations Environment Program: Nairobi, Kenya, 1995; pp. 166-173.

12. Searles, P.S.; Flint, S.D.; Caldwell, M.M. A meta-analysis of plant field studies simulating stratospheric ozone depletion. Oecologia 2001, 127, 1-10. [CrossRef] [PubMed]

13. Jansen, M.A.K. Ultraviolet-B radiation effects on plants: Induction of morphogenic responses. Physiol. Plant. 2002, 116, 423-429. [CrossRef]

14. Jenkins, G.I. Signal transduction in responses to UV-B radiation. Annu. Rev. Plant Biol. 2009, 60, 407-431. [CrossRef] [PubMed]

15. Jordan, B.R. The effects of ultraviolet-B radiation on plants: A molecular perspective. Adv. Bot. Res. 1996, $22,97-162$.

16. Jansen, M.; Bornman, J.F. UV-B radiation: From generic stressor to specific regulator. Physiol. Plant. 2012, 145, 501-504. [CrossRef]

17. Kazan, K.; Manners, J.M. The interplay between light and jasmonate signalling during defence and development. J. Exp. Bot. 2011, 62, 4087-4100. [CrossRef] [PubMed]

18. Li, W.F.; Mao, J.; Yang, S.J.; Guo, Z.G.; Ma, Z.H.; Dawuda, M.M.; Zuo, C.W.; Chu, M.Y.; Chen, B.H. Anthocyanin accumulation correlates with hormones in the fruit skin of 'Red Delicious' and its four generation bud sport mutants. BMC Plant Biol. 2018, 18, 363-377. [CrossRef] [PubMed]

19. Loreti, E.; Povero, G.; Novi, G.; Solfanelli, C.; Alpi, A.; Perata, P. Gibberellins, jasmonate and abscisic acid modulate the sucrose-induced expression of anthocyanin biosynthetic genes in Arabidopsis. New Phytol. 2008, 179, 1004-1016. [CrossRef] [PubMed]

20. Samuolienè, G.; Duchovskis, P.; Urbonavičiūtè, A. Phytohormones dynamics during flowering initiation in carrots. Acta Biol. Szeged. 2005, 49, 33-37.

21. Kobayashi, M.A.Y.; Mondal, M.F.; Ban, T.; Matsubara, H.; Adachi, F.; Asao, T. Growing carrots hydroponically using perlite substrates. Sci. Hortic. 2013, 159, 113-121. [CrossRef]

22. Singleton, V.L.; Rossi, J.A. Colorimetry of total phenolics with phosphomolybdic-phosphotungstic acid reagents. Am. J. Enol. Viticult. 1965, 16, 144-158. 
23. Großkinsky, D.K.; Albacete, A.; Jammer, A.; Krbez, P.; van der Graaff, E.; Pfeifhofer, H.; Roitsch, T. A rapid phytohormone and phytoalexin screening method for physiological phenotyping. Mol. Plant 2014, 7, $1053-1056$. [CrossRef] [PubMed]

24. Martens, H.J.; Sørensen, S.; Burow, M.; Veierskov, B. Characterization of Top Leader Elongation in Nordmann Fir (Abies nordmanniana). J. Plant Growth Regul. 2019, 1-8. [CrossRef]

25. Robson, T.M.; Aphalo, P.J.; Banaś, A.K.; Barnes, P.W.; Brelsford, C.C.; Jenkins, G.I.; Kotilainen, T.K.; Łabuz, J.; Martínez-Abaigar, J.; Morales, L.O.; et al. A perspective on ecologically relevant plant-UV research and its practical application. Photochem. Photobiol. Sci. 2019, 18, 970-988. [CrossRef] [PubMed]

26. Robson, T.M.; Klem, K.; Urban, O.; Jansen, M.A. Re-interpreting plant morphological responses to UV-B radiation. Plant Cell Environ. 2015, 38, 856-866. [CrossRef] [PubMed]

27. Frohnmeyer, H.; Staiger, D. Ultraviolet-B radiation-mediated responses in plants. Balancing damage and protection. Plant Physiol. 2003, 133, 1420-1428. [CrossRef]

28. Cisneros-Zevallos, L. The Use of Controlled Postharvest Abiotic Stresses as a Tool for Enhancing the Nutraceutical Content and Adding-Value of Fresh Fruits and Vegetables. Food Sci. 2003, 68, 1560-1565. [CrossRef]

29. Solovchenko, A.; Merzlyak, M.N. Screening of Visible and UV Radiation as a Photoprotective Mechanism in Plants. Russ. J. Plant Physiol. 2008, 55, 719-737. [CrossRef]

30. Agati, G.; Tattini, M. Multiple functional roles of flavonoids in photoprotection. New Phytol. 2010, 186, 786-793. [CrossRef]

31. Mittler, R. Oxidative stress, antioxidants and stress tolerance. Trends Plant Sci. 2002, 7, 405-410. [CrossRef]

32. Fini, A.; Brunetti, C.; Di Ferdinando, M.; Ferrini, F.; Tattini, M. Stress-induced flavonoid biosynthesis and the antioxidant machinery of plants. Plant Signal Behav. 2011, 6, 709-711. [CrossRef] [PubMed]

33. Li, B.; Krumbein, A.; Neugart, S.; Li, L.; Schreiner, M. Mixed cropping with maize combined with moderate UV-B radiations lead to enhanced flavonoid production and root growth in faba bean. J. Plant Interact. 2012, 7, 1-8. [CrossRef]

34. Schreiner, M.; Krumbein, A.; Mewis, I.; Ulrich, C.; Huyskens-Keil, S. Short-term and moderate UV-B radiation effects on secondary plant metabolism in different organs of nasturtium (Tropaeolum majus L.). Innov. Food Sci. Emerg. Technol. 2009, 10, 93-96. [CrossRef]

35. Neugart, S.; Zietz, M.; Schreiner, M.; Rohn, S.; Kroh, L.W.; Krumbein, A. Structurally different flavonol glycosides and hydroxycinnamic acid derivatives respond differently to moderate UV-B radiation exposure. Physiol Plant. 2012, 145, 582-593. [CrossRef] [PubMed]

36. Poorter, H.; Villar, R. Fate of acquired carbon in plants: Chemical composition and construction costs. In Plant Resource Allocation; Bazzaz, F.A., Grace, J., Eds.; Academic Press: San Diego, CA, USA, 1997; pp. 39-72.

37. Nithia, S.M.J.; Shanthi, N.; Kulandaivelu, G. Different responses to UV-B enhanced solar radiation in radish and carrot. Photosynthetica 2005, 43, 307-311. [CrossRef]

38. Tong, H.; Leasure, C.D.; Hou, X.; Yuen, G.; Briggs, W.; He, Z.H. Role of root UV-B sensing in Arabidopsis early seedling development. Proc. Natl. Acad. Sci. USA 2008, 105, 21039-21044. [CrossRef] [PubMed]

39. Potters, G.; Pasternak, T.P.; Guisez, Y.; Palme, K.J.; Jansen, M.A. Stress-induced morphogenic responses: Growing out of trouble? Trends Plant Sci. 2007, 12, 98-105. [CrossRef]

40. Vanhaelewyn, L.; Prinsen, E.; Van Der Straeten, D.; Vandenbussche, F. Hormone-controlled UV-B responses in plants. J. Exp. Bot. 2016, 67, 4469-4482. [CrossRef]

41. Korasick, D.A.; Enders, T.A.; Strader, L.C. Auxin biosynthesis and storage forms. J. Exp. Bot. 2013, 64, $2541-2555$. [CrossRef]

42. Köllmer, I.; Novak, O.; Strnad, M.; Schmülling, T.; Werner, T. Overexpression of the cytosolic cytokinin oxidase/dehydrogenase (CKX7) from Arabidopsis causes specific changes in root growth and xylem differentiation. Plant J. 2014, 78, 359-371. [CrossRef]

43. Kudo, T.; Makita, N.; Kojima, M.; Tokunaga, H.; Sakakibara, H. Cytokinin activity of cis-zeatin and phenotypic alterations induced by overexpression of putative cis-zeatin-O-glucosyltransferase in rice. Plant Physiol. 2012, 160, 319-331. [CrossRef] [PubMed]

44. Hayes, S.; Velanis, C.N.; Jenkins, G.I.; Franklin, K.A. UV-B detected by the UVR8 photoreceptor antagonizes auxin signaling and plant shade avoidance. PNAS 2014, 111, 11894-11899. [CrossRef] [PubMed] 
45. Rakitin, V.Y.; Karyagin, V.V.; Rakitina, T.Y.; Prudnikova, O.N.; Vlasov, P.V. UV-B stress-induced ABA production in Arabidopsis thaliana mutants defective in ethylene signal transduction pathway. Russ. J. Plant Physiol. 2008, 55, 854-856. [CrossRef]

46. Gajdosová, S.; Spíchal, L.; Kamínek, M.; Hoyerová, K.; Novák, O.; Dobrev, P.I.; Galuszka, P.; Klíma, P.; Gaudinová, A.; Zizková, E.; et al. Distribution, biological activities, metabolism, and theconceivable function of cis-zeatin-type cytokinins in plants. J. Exp. Bot. 2011, 62, 2827-2840. [CrossRef] [PubMed]

47. Kurakawa, T.; Ueda, N.; Maekawa, M.; Kobayashi, K.; Kojima, M.; Nagato, Y.; Sakakibara, H.; Kyozuka, J. Direct control of shoot meristem activity by a cytokinin-activating enzyme. Nature 2007, 445, 652-655. [CrossRef]

48. Escobar Bravo, R.; Chen, G.; Grosser, K.; Van Dam, N.M.; Leiss, K.A.; Klinkhamer, P.G.L. Ultraviolet radiation enhances salicylic acid-mediated defense signaling and resistance to Pseudomonas syringae DC3000 in a jasmonic acid-deficient tomato mutant. Plant Signal. Behav. 2019, 14, e1581560. [CrossRef] [PubMed]

(C) 2019 by the authors. Licensee MDPI, Basel, Switzerland. This article is an open access article distributed under the terms and conditions of the Creative Commons Attribution (CC BY) license (http://creativecommons.org/licenses/by/4.0/). 